THURSDAY, MARCH 7, I872

\section{A FRENCH ASSOCIATION FOR THE ADVANCEMENT OF SCIENCE}

$\mathrm{N}$ France there is at the present time a movement of 1 regeneration in the scientific world, slow indeed, and difficult to be seen through the troubles on the surface, but the evidence of it is incontestable. The actual activity is great; publications of every kind appear, some quite new, as the Foumal de Physique, the Archives de Zoologie; others improved and extended, as the Annales de l'Ecole Normale. The Comptes Rendus of the Paris Academy, which are the weekly résumé of French science, have rarely been so full of important memoirs, while research, almost dead to England, promises regeneration for French science.

To take a recent example of this activity, we may cite about fifty notices relative to the aurora borealis of last month, coming from every part of France. This amount of attention paid to a phenomenon which, a few years ago, would have excited nothing more than a mere curiosity, evidences the actual aspirations connected with, and a natural taste for, scientific subjects. But what must specially strike the English scientific world is the recent foundation of a French Association for the Advancement of Science, on the model of the British Association, without any other modifications than those which must result from the different characters of the two nations.

Though this proposal has not reached its complete extension (no publicity having been as yet given to it) it is possible, from the rapidity with which the working committee was constituted, the large amount of money collected, and the sympathies expressed on all sides, to predict for the younger sister of the British Association a great success.

The proposed statutes, which have been drawn up and provisionally adopted at a series of meetings at which MM. Balard, Berthelot, Briot, Broca, Claude Bernard, Combes, Cornu, Decaisne, Delaunay, Descloiseaux, De Luynes, Dumas, Friedel, P. Gervais, A. Girard, G. Hachette, Lacaze-Duthiers, Laugier, Levasseur, Loewy, Marié-Davy, V. Masson, Pasteur, Serret, Tisserand, and Wurtz were present, are as follows :-

ART. I.-The Association proposes to favour by every means in its power the progress of tixe sciences, their practical application, and the diffusion of scientific knowledge. For this purpose it will exercise its infuence principally by meetings, conferences, and publications; by gifts of instruments or money to persons engaged in researches, observations, or experiments, scientific enterprises which it would have approyed or provoked. It appeals to all those who consider the culture of the sciences as necessary to the greatness and prosperity of France.

ART. II.-The Association is established with a capital divided into shares of 500 francs each, subscribed by members wiso take the title of founders. It will commence its operations as soon as 200 of these shares, forming a capital of 100,000 francs, shall have been subscribed."

ART. IlI. - The Association shall consist of founders and ordinary associalcs, who shall pay an annual subscription of

* This amount has been exceeded some wecks since. It was subscribed by scientific men, and by the greater number of the councils of the railway, industrial, and financial companies.

vol. V.
20 fancs. This subscription can always be compounded by the payment of the sum of 200 francs once for ail.

ART. IV.--The number of founders or associates is unlimited, and all enjoy the same privileges. The names of the founders shall, however, always appear at the head of the lists, and these members receive gratuitousiy and for ever all the publications of the Association, as many c pies as they have subscribed shares of 500 r.

ART. V. - The seat of the Council of the Association shall be at Paris.

ART. VI.--Each year the Association shall hold in one of the towns of France a general session, the duration of which shall be eight days.

ART. VII. - In the general session the Association shall be divided into sections, of which the number and functions shall be fixed by the general assembiy on the proposition of the Council. These sections shall be attached to the four groups of Mathematical, Physical and Chemical, Natural, and Economical and Statistical science. Every member of the Association shall choose each year the section to which he wishes to belong. He can nevertheless take part in the work of the other sections, but only with consultative voice (voix consilitative.)

ART. VIII. - The bureau of the Association is composed:$\mathrm{I}$, of the president and secretary ; 2 , of the presidents and secretaries of sections; 3 , of the treasurer and the libratian.

ART. IX.-The Association shall be managed gratuitously by a Council composed-I, of the bureat of the association; 2 , of members elected in the general assembly to the number of three by each section,

ART. X.-At the commencement of each session the presidents, vice-presidents, and secretaries of the sections are nominated directly by a relative majority of the sections.

At the end of each session, the Association, united in general assembly, shall name the town where the following session shall take place, fix a programme for that session, and nominate by relative majority the president and secretary for the following year, and also the members of the Council.

The president and secretary shall be taken in turn from each of the four sections. If either is prevented from attending, he sirall be replaced by one of the presidents or secretaries of the divisions of the section to which he may belong.

Aner. Xl.-The Council charged with the organisation of the session in the town selected can for that purpose elect an honorary president.

ART. XII.-All members of the Association are asked to take part in elections by voting either in person or by letter (par correspondence).

AnT. XIIL.-The Council represents the Association. It has full power to carry on and administer the social business, both active and passive. It shall receive all funds belonging to the Association, of whatever kind they may be. It shall invest in Government securities the funds arising from the shares subscribed by the founders, and from the compounding of annual subscriptions by the associates. It shall superintend the expenditure of the disposable funds voted by the Association on its proposal. It shall make all rules necessary for maintaining internal order and the execution of the present statutes. It shall convoke the Association, and arrange the programme of the meeting, in conformity with deliberations made in the general assembly.

The Council shall nominate and constitute the special committees for the funds for encouragements, for publications, and for conferences.

The Council slall deliberate in due form and by the majority of members present; neveraheless no resolution shall be valid unless it shall have been deiberated upon in the presence of onefourth, at least, of the members of the Council.

ART. XIV.-The Council shall prepare annually the buclget of expenses of the Association, and shall read in the annual general session a detailed account of receipts and expenses of work themselves (de l'enzercice écoublé).

ART. XV. - The statutes can be modified on the proposition of the Council, and by a majority of two-thirds vo ing in the general assembly. The proposed modifications shall be indicated beforehand in the Convocatory letters addressed to all members of the Association.

\section{Proposed SECtions}

Ist Section-Mathentical Science Ist, Division of Mathematics, Astronomy, and Geodetical 
Science; and Mechanics; 3 rd, Navigation; 4 th, Civil and Military Engineering.

and Section-Chemical and Physical Science

$5^{\text {th }}$, Physics; 6th, Chemistry; 7th, Meteorology and Physics of the Globe.

3rd Section-Natural Sciences

8th, Zoology and Zootechny; 9th, Botany; Ioth, Geology and Mineralogy; I Itb, Medicine.

$4^{\text {th Section-Economic Sciences }}$

I2th, Agriculture (Agronomie); I3th, Ethnography and Geography; I $4^{\text {th }}$, Statistics.

We are told that certain modifications may be introduced before the final constitution of the Association, but they are not likely to change the general character of the institution.

Amongst the promoters of this Association are to be found the names most celebrated in French science, showing that this scientific movement is a general one, and answers to a pressing want.

A peculiar feature will be remarked : the general spirit of the statutes denotes a very decided tendency to decentralisation. Up to the present time French science has had the reverse tendency,--to attract to Paris all the intelligent strength of the nation. The result, most excellent for Paris, which constitutes one of the greatest scientific centres in the world, has been very disadvantageous for the country. The provincial facultés (local universities) have been deprived of the most important of their members, and are actually very far from answering to the scientific standard of the metropolis. If we add now that the Ministere de l'Instruction Publique not only has insufficient funds for these institutions of higher instruction, but considers the facultés as sources of revenue by the granting of degrees, it will be understood that it is the right time to act vigorously to raise the taste for science in the parts of the country remote from the capital.

Too much encouragement cannot be given to the founders of the French Association in their task of decentralising science in France. The first result will be to create real scientific centres, vigorous with a new life, and diffusing a great activity. It cannot be objected that the genius of the nation is opposed to such a decentralisation, and that all aspirations must necessarily converge towards Paris. This is an error. The town of Montpellier gives the example of a Faculté de Médecine, of which the reputation is scarcely inferior to the Paris faculté. It is equally certain that Toulouse the town of Feuxfloraux, Lyons, Marseilles, Clermont, and many others, under a vigorous impulse, could also become great scientific centres. To aim at this object, nothing will be better than to show every year the whole scientific corps of Paris, the scientific Etat-major transporting itself to a remote city or town, liberally giving lectures and conferences, and promoting researches and experiments. Thus the metropolis will greatly help the scientific renovation, and will show that it wishes not to attract to itself the whole force and consideration, but to diffuse its own energy over the whole country.

It is probable that the first meeting will be held this year at Lyons, the second town of France, at the end of August or the beginning of September. To the interest of the meeting would be added the attraction of a great industrial exhibition.
We cannot do otherwise than wish a great success to the French Association. We are happy to see that all parties are uniting in their exertions in such a direction; that a good number of associates, independent or belonging to scientific societies, are giving in their adhesion to the new association. Amongst the congratulations which the Association ought to receive at its birth, no doubt one of the first will be addressed by the British Association. This will be for England both a duty and an honour. A nation must always? be happy to be valued and proud to be imitated.

\section{QUETELET'S CONTRIBUTIONS TO THE SCIENCE OF MAN}

Physique Sociale, ou Essai sur le. Dézeloppenent des Facultés de l'Homne. Par Ad. Quetelet. (Brussels, 1869.)

Anthropométrie, ou Mesure des différentes Facultés de l'Homme. Par Ad. Quetelet. (Brussels, i87o.)

TWO lines of research into the Science of Man, of the 1 highest moment as well in theoretical Anthropology as in practical Ethics and Politics, both to be always associated with the name of Quetelet, are now discussed at large in his Social Physics and Anthropometry. The two great generalisations which the veteran Belgian astronomer has brought to bear on physiological and mental science, and which it is proposed to describe popularly here, may be briefly defined. First, he has been for many years the prime mover in introducing the doctrine that human actions, even those usually considered most arbitrary, are in fact subordinate to general laws of human nature; this doctrine, maintained in previous publications, especially in the earlier edition of the first-named work some thirty-seven years ago, is now put forth in its completest form. Second; he has succeeded in bringing the idea of a biological type or specific form, whether in bodily structure or mental faculty, to a distinct calculable conception, which is likely to impress on future arguments a definiteness not previously approached.

The doctrine of the regularity and causality of human actions was powerfully stated some fifteen years ago by Mr. Buckle in the introduction to his "History of Civilisation." Buckle is here essentially the exponent of Quetelet's evidence, from which, indeed, as a speculative philosopher he draws inferences more extreme than those of his statistical teacher. To Quetelet is due the argument from the astonishing regularity from year to year in the recurrences of murders and suicides, a regularity extending even to the means or instruments by which these violent acts are committed; his inference being broadly "that it is society which prepares the crime, the criminal being only the instrument which executes it." From various other sources Buckle brought together other pieces of evidence, especially one which is now quoted by all who discuss the subject, the regularity from year to year of letters posted, whose writers forget to direct them. It may by this time be taken as proved by such facts that each particular class of human actions may be estimated, and to a great extent even predicted, as a regular product of a definite social body under definite conditions. To quote another luminous instance of this regularity of 